\title{
Influence of Different Plates Arrangements on the Car Body
}

\author{
Krzysztof Kurec ${ }^{1, *}$, Konrad Kamieniecki ${ }^{1}$ and Janusz Piechna ${ }^{2, *}$ (D) \\ 1 Institute of Micromechanics and Photonics, Warsaw University of Technology, Sw. A. Boboli 8, \\ 02-525 Warsaw, Poland; konrad.kamieniecki@pw.edu.pl \\ 2 Institute of Aeronautics and Applied Mechanics, Warsaw University of Technology, Nowowiejska 24, \\ 00-665 Warsaw, Poland \\ * Correspondence: krzysztof.kurec@pw.edu.pl (K.K.); jpie@meil.pw.edu.pl (J.P.)
}

Citation: Kurec, K.; Kamieniecki, K.; Piechna, J. Influence of Different Plates Arrangements on the Car Body. Energies 2022, 15, 619. https:// doi.org/10.3390/en15020619

Academic Editor: Antonio Crespo

Received: 7 December 2021

Accepted: 11 January 2022

Published: 16 January 2022

Publisher's Note: MDPI stays neutral with regard to jurisdictional claims in published maps and institutional affiliations.

Copyright: (C) 2022 by the authors. Licensee MDPI, Basel, Switzerland. This article is an open access article distributed under the terms and conditions of the Creative Commons Attribution (CC BY) license (https:// creativecommons.org/licenses/by/ $4.0 /)$.

\begin{abstract}
The purpose of this study was to investigate whether small plates covering the roof and the hood of the DrivAer estate vehicle can be used as airbrakes and increase its drag as well as the downforce. The presented results were obtained with the use of the commercial computational fluid dynamics software ANSYS ${ }^{\circledR}$ Fluent. The main findings of the article are that the aerodynamic devices such as flaps covering surfaces of the vehicle can have a significant impact on drag increase and can be used not only to make the design of the car more striking but also beneficial when utilized as a part of an active aerodynamic setup.
\end{abstract}

Keywords: CFD; automobile aerodynamics; active aerodynamics

\section{Introduction}

In recent years, active aerodynamics began to focus more and more attention. Active aerodynamic enables the modification of the aerodynamic properties of a vehicle to aid its driving properties depending on the current weather, terrain, road conditions, reduce vibrations of the vehicle body caused by uneven road surfaces, improve tire adhesion to the uneven road surface, improve safety during maneuvers of changing lanes, and overtaking or when driving on a curve.

Active aerodynamics is the most influential at high speed because the aerodynamic forces depend on the square of the velocity. Most research focuses on the control algorithms [1-3], whereas how the aerodynamic forces are being generated is given less attention. In most cases, it is presumed that the required aerodynamic load will be generated by a rear or front wing. However, if the active aerodynamics are to be influential on a car's driving properties, high values of the aerodynamic forces need to be applied, or in some events, they need to be generated very quickly or with a high frequency. Wings are most efficient when mounted on the rear of the car, which strictly limits where the aerodynamic load is applied. Wings also need to have big dimensions with high span and chord values to generate high aerodynamic loads. Moreover, with the increase in the size, such an aerodynamic device cannot be moved very quickly, which delays its action or even limits its capabilities by making it impossible to generate aerodynamic loads changing with a high frequency, which would be required for dumping the vibrations of the car body.

Small movable aerodynamic elements have several advantages. In the inactive state, they can be invisible by retracting back into the car body and decreasing the drag coefficient, whereas, in the active state, they can position themselves at different angles. Due to their small size and a low mass of the moving parts, they can quickly change their configuration without using powerful actuators that would consume substantial amounts of energy. They could be utilized in the active aerodynamics systems instead of the large, movable wings that are used most often. Usually, large movable aerodynamic elements in the form of wings are used. A thorough review of such solutions on their advantages and disadvantages is included in [4]. 
Sets of small movable aerodynamic elements could be an interesting alternative to the currently considered aerodynamic actuators. In various configurations, they can act as aerodynamic brakes, generators of lateral forces, and aerodynamic moments partially compensating for the side-to-side inclination of the car under the influence of inertial forces in corners or when subjected to side winds.

Inverted wings used in Time Attack races are large elements located in front of and above the car body with a complicated mounting system and are not suitable for road cars. In the case of wings located close to the body in the front part, there is a very strong interaction between them which significantly reduces aerodynamic downforce, as shown in [5]. Sets of small moving aerodynamic elements located on the body could be utilized not to cause such adverse effects. Some of the other traditional aerodynamic elements utilized in an active aerodynamic system are described in [4-6].

The above issues motivated the authors of this manuscript to investigate methods of generating aerodynamic loads using small elements [7], which makes them more versatile. It would be best to attach them to any part of the car body and retract within it when there is no need to use them. Small dimensions would allow moving much faster than a typical wing and obtain aerodynamic loads at high frequencies. However, when an aerodynamic device is being downsized, the load that it generates lowers due to a decrease in its surface, which makes it less efficient. That is why obtaining aerodynamic loads by different means than a typical wing would be desired. The 2009 BMW Lovos concept car designed by Anne Forschner attracted the authors' attention. That concept car included 260 plates inspired by fish scales, either closed (Figure 1a) or opened (Figure 1b).

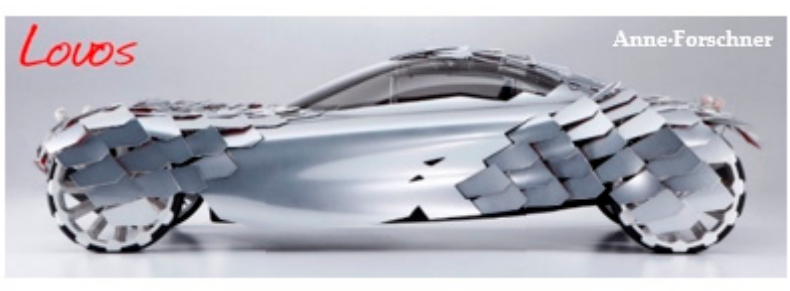

(a)

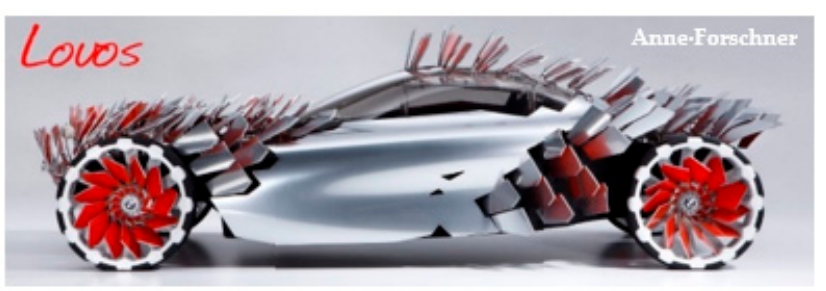

(b)

Figure 1. BMW Lovos concept by Anne Forschner with (a) closed scales and (b) opened scales. Images courtesy of Anne Forschner [8].

When the plates are opened, they can work as an airbrake. Their additional functionality is that they can be utilized as solar cells, and because they can move, they can catch the sunbeams in the most effective way possible in given conditions. This concept car looks very interesting, but the main question that arises is whether all these plates can generate aerodynamic loads while most of them are located in the aerodynamic wake of the plates to the front, which makes them obsolete in terms of generating aerodynamic loads. So, the question is whether such a big number of plates could be used as an efficient airbrake.

A more recent concept car, the Mercedes-Benz VISION AVTR [9] presented in 2020, also incorporates the idea of moving plates. The moving plates called bio-flaps cover only the surface of the rear slant with the 33 flaps called "bionic flaps". The general idea of their use is similar to the previously brought-up concept design. These plates also have the capabilities to affect the aerodynamic properties of the car and act as solar plates. However, this design is more conservative while considering the area covered by the plates.

With the development of the shape memory alloys [10], with the more detailed description of the specific aerodynamic elements and their actuation mechanisms presented in $[11,12]$, it is becoming possible to design a car that would take advantage of several moving elements on its body with fewer technology limitations on the way.

This work aims to determine the potential effectiveness of flaps covering the hood and the roof area of a car body. It was investigated whether several rows of elements could be effective, or only the first row would generate aerodynamic forces, and the ones further 
down the flow stream would become obsolete. The focus was put on the configurations that could act as an airbrake.

\section{Materials and Methods}

The results presented in this study were obtained using commercial solver Ansys ${ }^{\circledR}$ Fluent. The DrivAer [13] car body was chosen as the object of the study, as it is commonly used in car aerodynamics. It resembles the shape of a real car without any significant simplifications. Out of the three available DrivAer models, the estate type was used. It has the longest roof section of all the variants, so it has the biggest area that can be covered in flaps. In this case, it also has one more advantage; unlike the fastback and the notchback variants, it does not have the lowered trunk section, so it is easier to keep the flow attached to its top surface. The model that was used had a smooth underbody.

The first approach was to locate the plates in place of conventional wings and spoilers. Figure 2 shows an example of the distribution of hexagonal plates on the upper surface of the car body. The basis for operating the sets of small movable aerodynamic elements is their variable axes of rotation. In the solution proposed for Mercedes Benz AVTR [14], a system of three movable arms with unique joints allowing any positioning of the circular disc was used. Our first idea was limited to adopting round and hexagonal-shaped plates, rotations about one of the six axes. A system of electromagnetically extending pins fixed one of the six axes, and a pneumatic or electromechanical system lifted the plate by rotating it around the fixed axis of rotation. For square plates, one of four axes of rotation could be selected. However, if the plates were to detach the flow from the car body, only a limited number of their rows could be mounted. The following rows would be obsolete due to placement in the wake of the plates in the front. After deliberation, it was concluded to use square plates with two directions of the rotation axes.

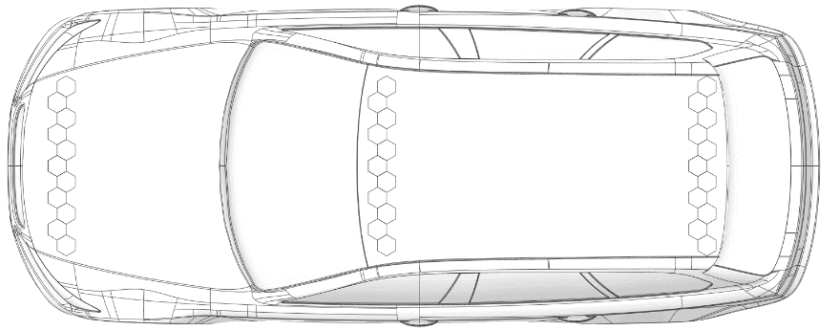

(a)

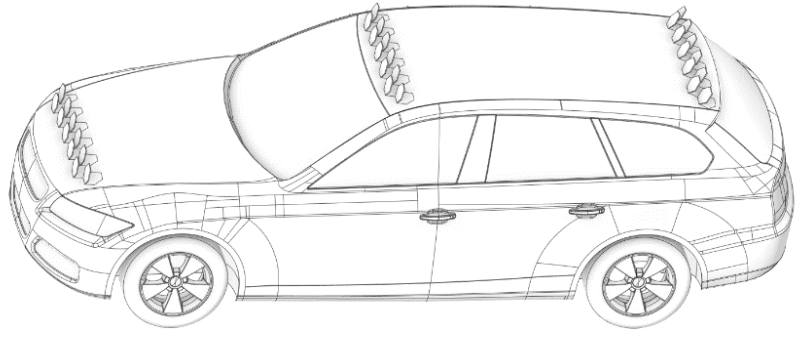

(b)

Figure 2. The DrivAer model with two sets of rows of hexagonal flaps mounted at the front edge of the hood, the front edge of the roof, and the rear edge of the roof: (a) top view with flaps inactive; (b) side view with plates ejected at an angle equal to $60^{\circ}$.

In the final approach, it was assumed that the surfaces of the roof (Figure 3a) and the hood could be covered with square flaps. Each flap had a $9 \mathrm{~cm}$ edge and was $5 \mathrm{~mm}$ thick. The dimensions were chosen arbitrarily to keep these elements relatively small. Plates were inclined at an angle equal to $45^{\circ}$ towards the edge of the windshield. Each plate could be rotated along its two sides (Figure $3 b, c)$, which enables the plate to point towards the left or the right side of the car. Such a configuration makes it possible to form different patterns of obstacles, with an example presented in Figure 3d,e. 


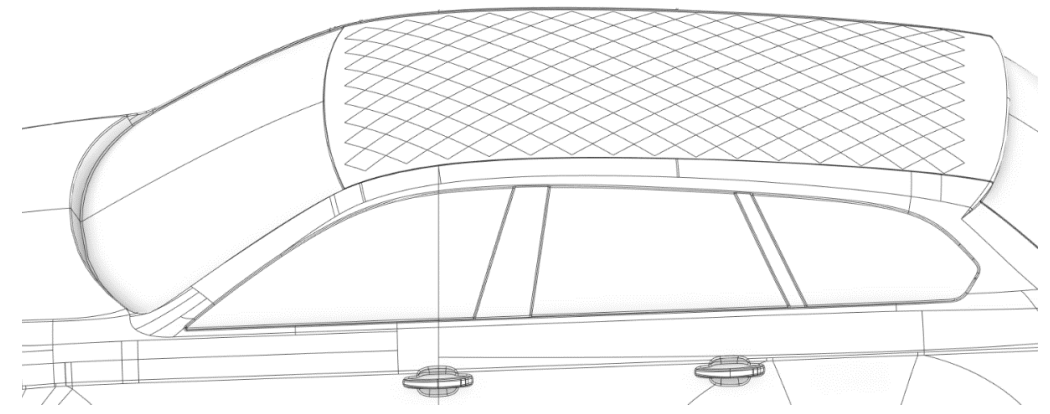

(a)

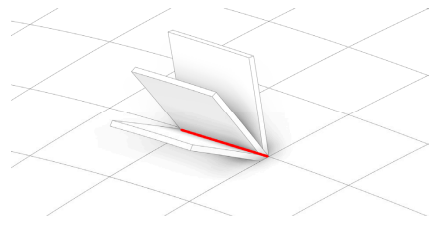

(b)

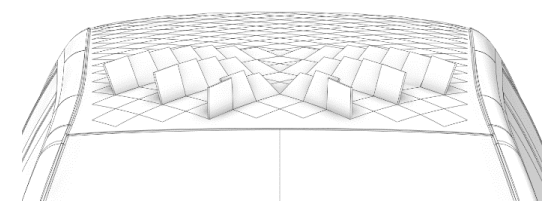

(d)

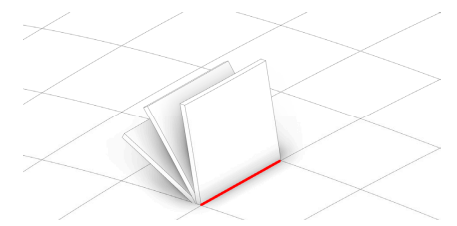

(c)

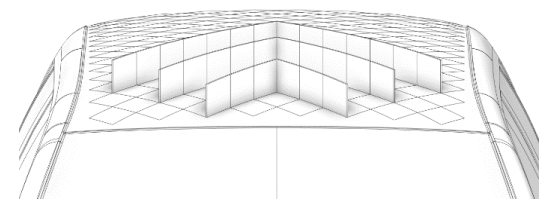

(e)

Figure 3. (a) Flaps covering the roof of the DrivAer model. Single flap rotated with its intermediate positions where it either ejects towards (b) the left side of the car or its (c) right side. Flaps are shown (d) while adjusting and (e) when rotated into the final position when they pose the maximum aerodynamic drag.

\section{Results}

All the calculations were performed in a steady state. The first calculations were performed on geometry without plates ejected from the car body. The realizable k-epsilon turbulence model was used with the Standard wall functions, so the mesh was created to fulfill requirements for $Y+$ values to stay in the range between 30 and 300 . The Ansys Fluent ${ }^{\circledR 囚}$ Mosaic Meshing was used to generate the computational domain, presented in Figure 4 . Ten layers of prism elements were created around the car body and the ground, including the cases with the plates ejected from the car body. There were no gaps between the geometry of the car body and the plates, which made it easier to create the inflation layers. Velocity inlet condition was set on the front face of the computational domain with the velocity magnitude set to $30 \mathrm{~m} / \mathrm{s}$, a turbulent viscosity ratio equal to 20, and a turbulent intensity equal to $1 \%$. The pressure outlet condition was set on the rear face of the domain and symmetry condition on the sides. The moving wall was set on the ground with speed set to $30 \mathrm{~m} / \mathrm{s}$. 


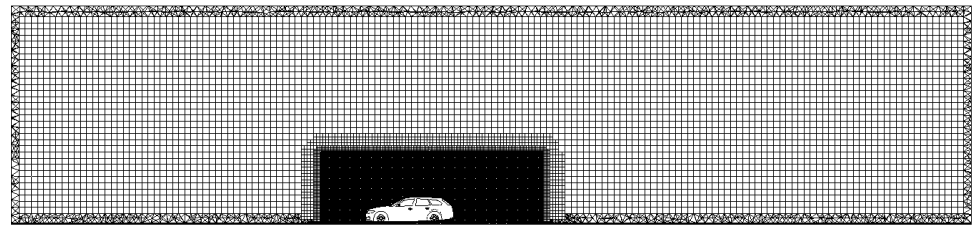

(a)

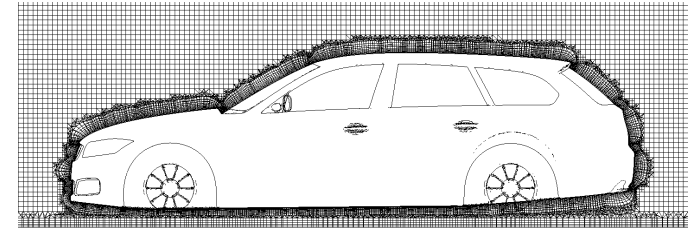

(b)

Figure 4. Mesh at the symmetry plane (a) wide of view and (b) close-up on the car.

\subsection{Grid Dependency Study}

The base mesh consisted of $10 \times 10^{6}$ cells. Values of the drag force and the lift forces were compared with the results on a coarser mesh $\left(2.8 \times 10^{6}\right.$ cells $)$ and a finer mesh $\left(51.7 \times 10^{6}\right.$ cells). In Figure $5 a, b$, it can be seen that the results on the base mesh and the finer mesh are on the same level, and that is why it was decided that the base mesh could be used in further investigations.

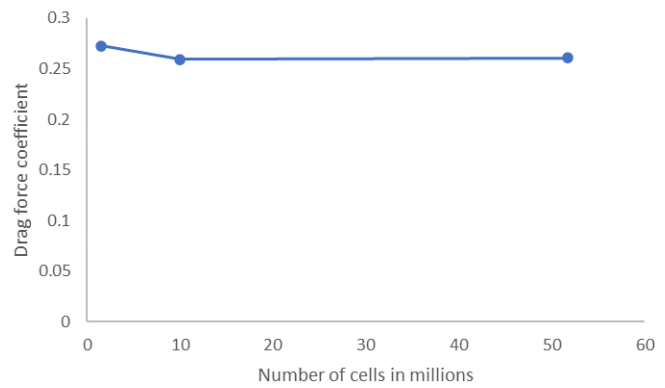

(a)

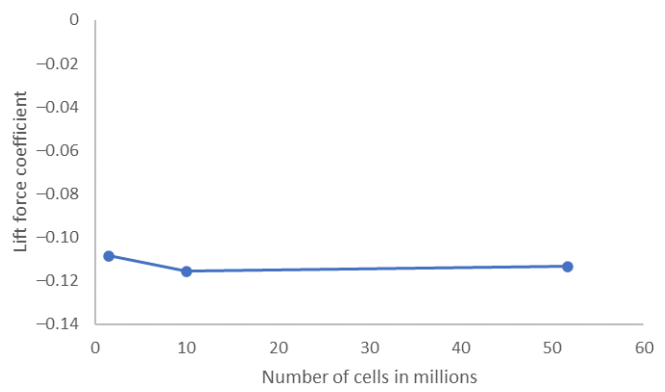

(b)

Figure 5. Values of (a) drag force coefficient and (b) lift force coefficients for different grid sizes used in calculations.

\subsection{Validation}

Experimental data presented in [15-17] were used to validate the CFD calculations on the DrivAer Estate type geometry without any modifications. In each case, the investigated model had a smooth underbody, non-rotating wheels, and was placed on a fixed ground. The obtained aerodynamic coefficients were compared with the experimental results [15] and displayed in Table 1. The pressure coefficient distribution from an experimental investigation presented in [16] from the Tongji facility with a fixed ground condition was set together with the CFD results (Figure 6) as well as normalized velocity contours on the symmetry plane obtained during PIV experiments included in the supplementary material included in [17] (Figure 7). As it is thoroughly described in [15], the RANS calculations of the DrivAer model are less accurate than DES. However, as shown in the figures, the most notable flow features were captured; hence it was decided to use RANS due to lower computational cost. Many different setups of the plates were investigated, and the most interesting ones were chosen to be presented. Performing all calculations in DES would consume too much time.

Table 1. Aerodynamic coefficients from experiments and CFD.

\begin{tabular}{ccc}
\hline Case & Drag Coefficient & Lift Coefficient \\
\hline Experiment & 0.294 & -0.120 \\
CFD & 0.259 & -0.116 \\
\hline
\end{tabular}




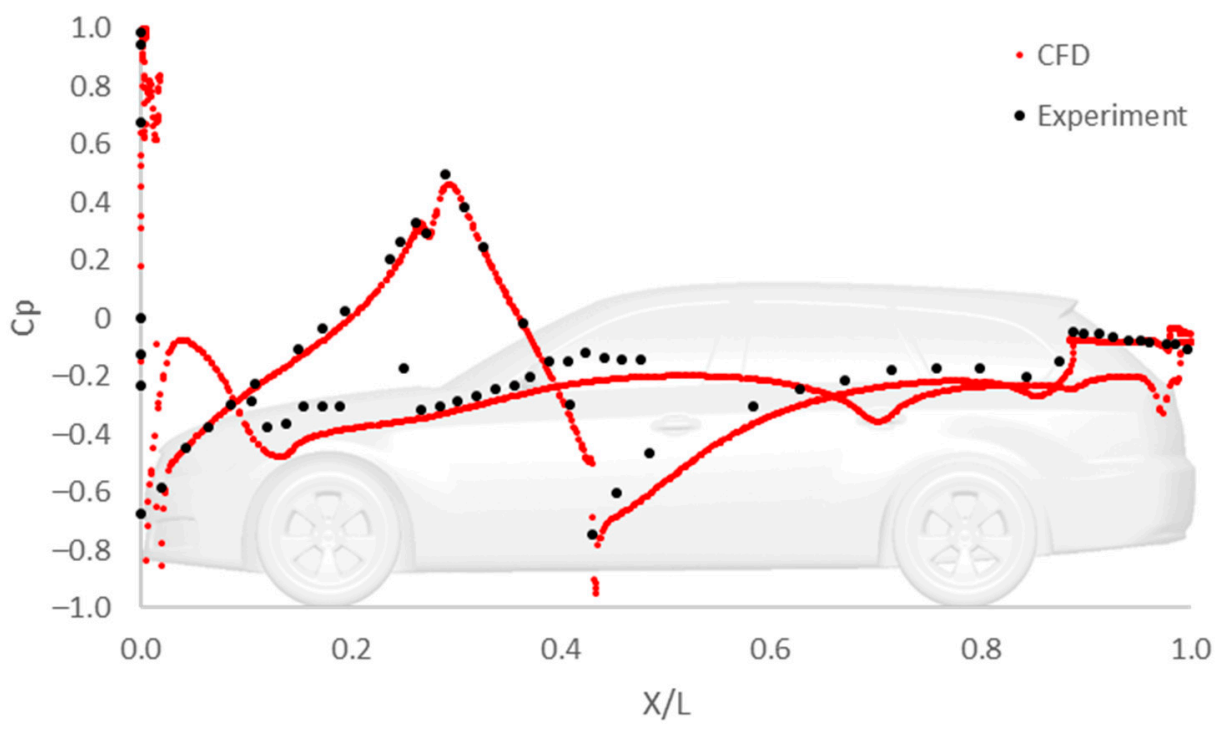

Figure 6. Pressure coefficient distribution along the car body at the symmetry plane compared with the experiment [16].

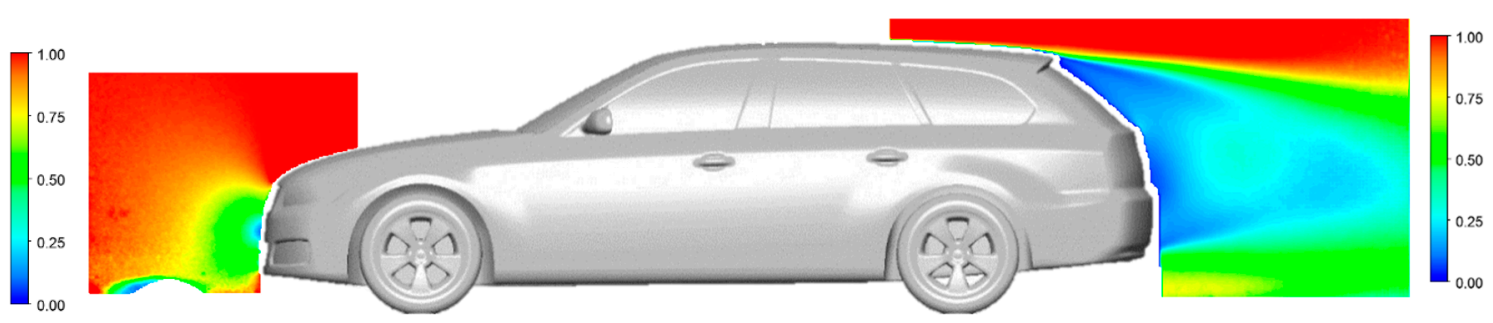

(a)

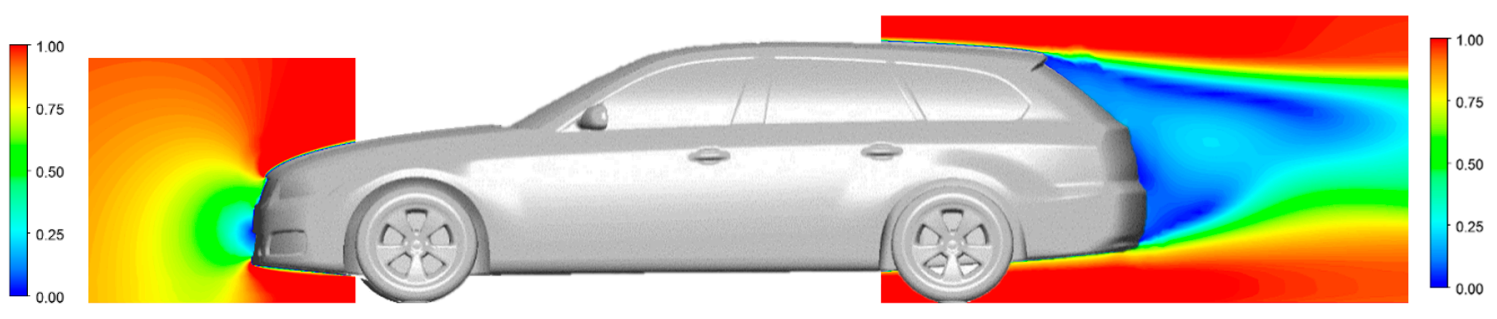

(b)

Figure 7. Comparison of contours of velocity normalized by velocity in the free stream from (a) PIV [17] and (b) CFD.

\subsection{Spoilers on the Roof}

The first set of the presented results focuses on showing the challenge of covering the whole area of the roof in aerodynamic devices. The spoiler in the shape of a plate was used (Figures 8 and 9). It can be seen in Figure 9 that when the spoiler is attached at the trailing edge of the roof, it generates an increase in pressure not only on itself but also on the roof in front of it. When the spoiler is located at the leading edge of the roof, the pressure is increased on the remaining frontal part of the roof but also the windshield. An increase in pressure on the windshield contributes to the increase in the downforce and the drag because, unlike the almost flat roof, the windshield is sloped, so it is particularly interesting, whereas aerodynamic braking is concerned. The apparent disadvantage of the spoiler located at the front is that it reduces pressure on the rest of the roof, which creates lift. What is more, the flow detaches from the roof (Figure 8), which means that any elements located 
there would become obsolete. To support this statement, results with the spoiler located at the front and the rear of the roof are presented. It can be seen in Table 2 that values of the aerodynamic drag do not add up when both of these spoilers are included, which means that putting several rows of these kinds of elements on the roof would not contribute to aerodynamic braking.

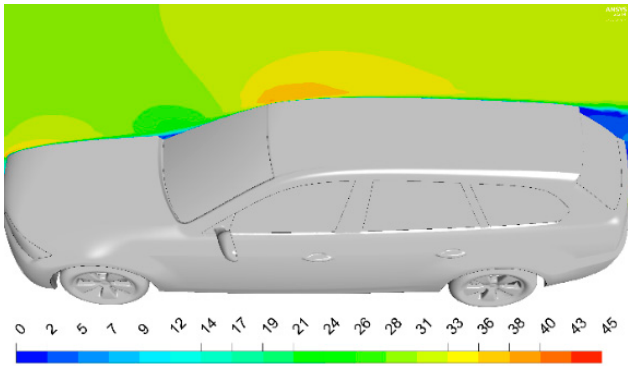

(a)

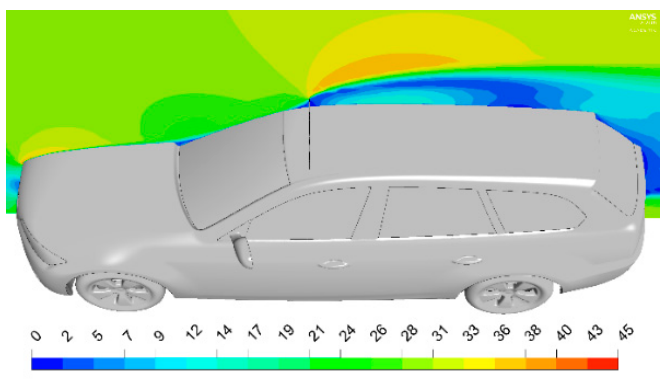

(c)

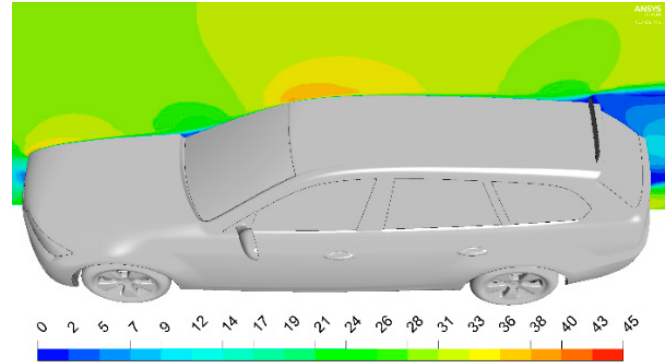

(b)

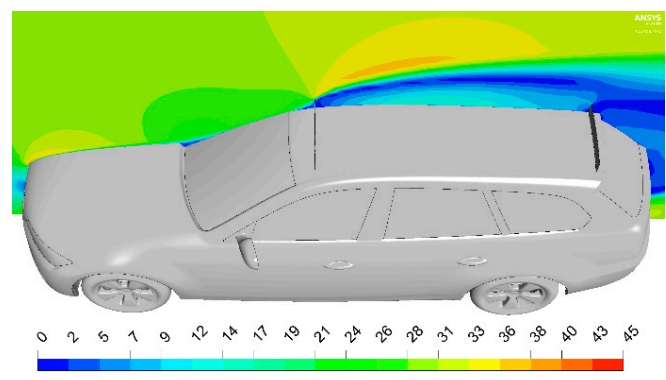

(d)

Figure 8. Velocity contours [m/s] on the symmetry plane: (a) base case; (b) rear spoiler; (c) front spoiler; $(\mathbf{d})$ rear and front spoiler.

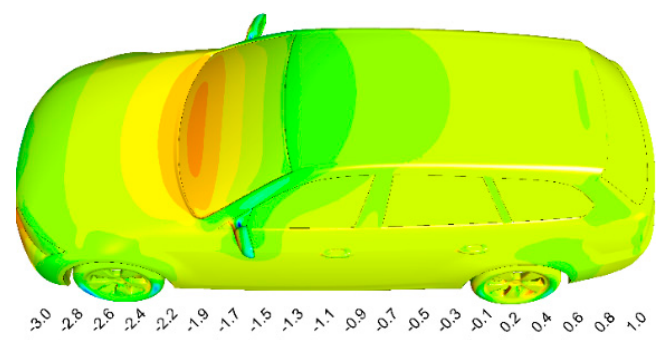

(a)

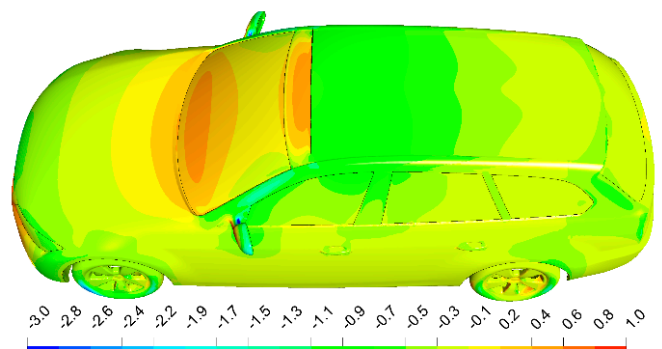

(c)

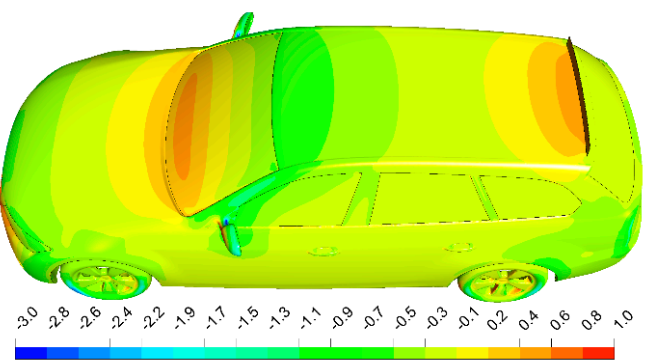

(b)

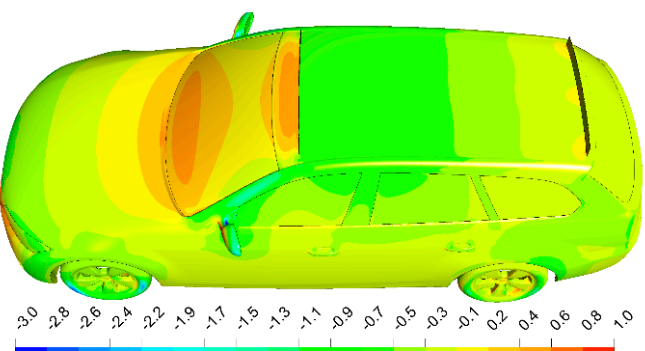

(d)

Figure 9. Pressure coefficient contours on the car body: (a) base case; (b) rear spoiler; (c) front spoiler; (d) rear and front spoiler. 
Table 2. Aerodynamic coefficients for different locations of the roof spoiler.

\begin{tabular}{ccccc}
\hline \multirow{2}{*}{ Case } & \multirow{2}{*}{$\begin{array}{c}\text { Drag } \\
\text { Coefficient }\end{array}$} & Lift Coefficient & \multicolumn{2}{c}{ Lift Distribution } \\
\cline { 4 - 5 } & 0.259 & -0.116 & Front & Rear \\
\hline Base & 0.402 & -0.328 & -0.147 & 0.031 \\
Rear spoiler & 0.359 & 0.051 & -0.011 & -0.190 \\
Front spoiler & 0.397 & -0.192 & -0.111 & -0.062 \\
Rear and front spoilers & & &
\end{tabular}

\subsection{Spoilers on the Hood}

In this section, problems concerning mounting a spoiler on the hood are examined. As expected, in this case, the flow around the whole car body is affected (Figure 10). The most significant differences can be observed on the hood and the windshield, but the pressure distribution on the roof is also affected (Figure 11).

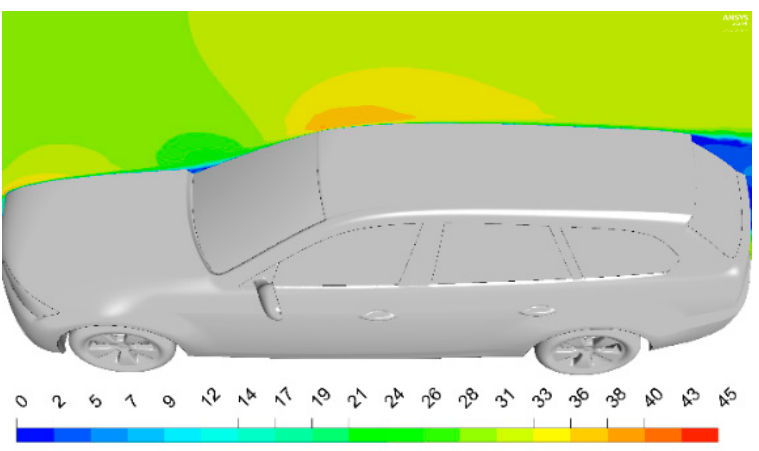

(a)

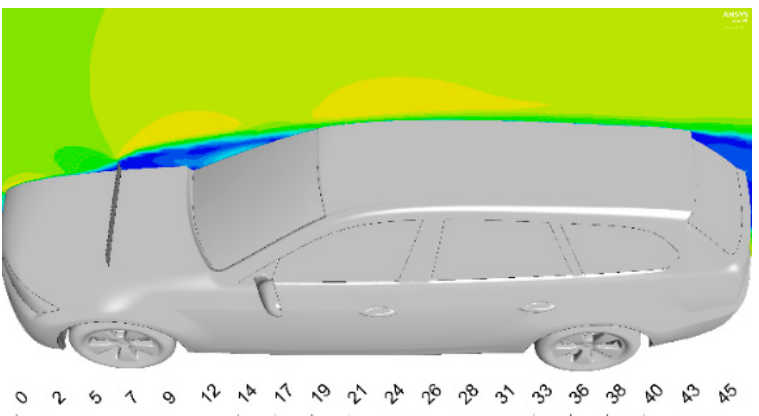

(c)

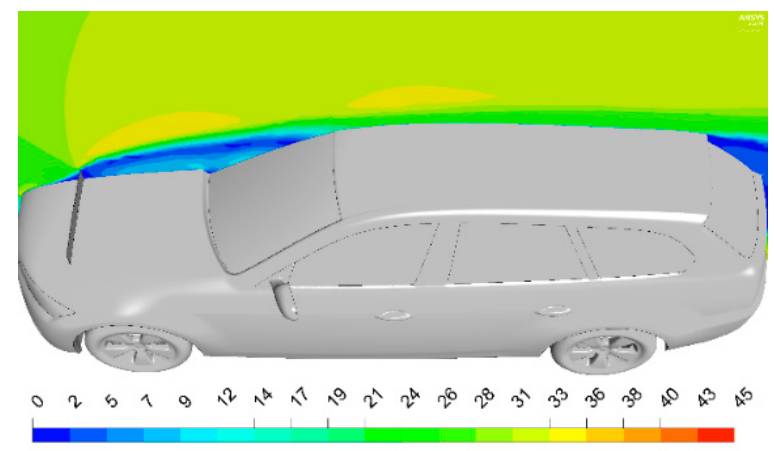

(b)

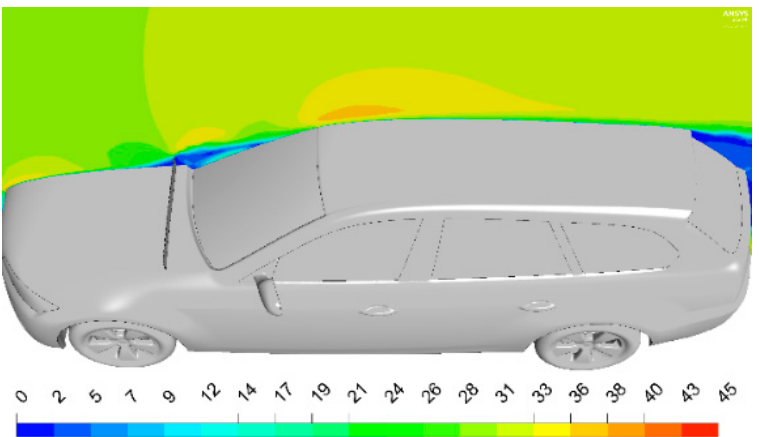

(d)

Figure 10. Velocity contours [m/s] on the symmetry plane: (a) base case; (b) hood spoiler $0.33 \mathrm{~m}$; (c) hood spoiler $0.66 \mathrm{~m}$; (d) hood spoiler $0.99 \mathrm{~m}$.

When the spoiler is located close to the leading edge of the hood, pressure in front of it increases, but it decreases on the rest of the hood and the windshield. Due to the formed recirculation zone, it can be noticed that the flow does not accelerate on the leading edge of the roof. This contributes to an increase in pressure on the top part of the windshield and the roof. Overall, an increase in drag and downforce can be observed (Table 3). Moving the mounting location of the spoiler towards the windshield minimizes the influence of this spoiler and creates the pressure distribution resembling the base case. 


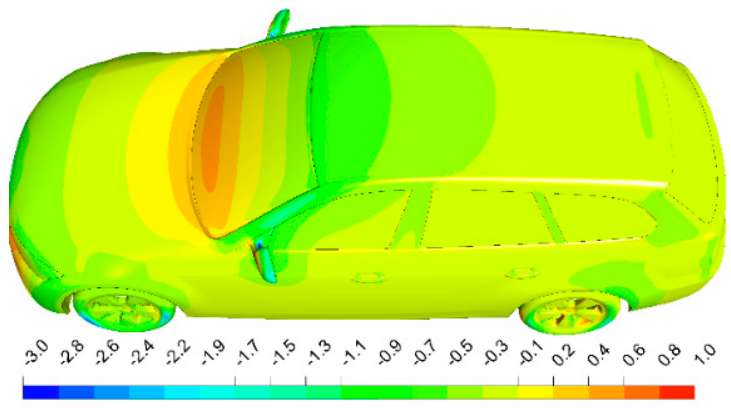

(a)

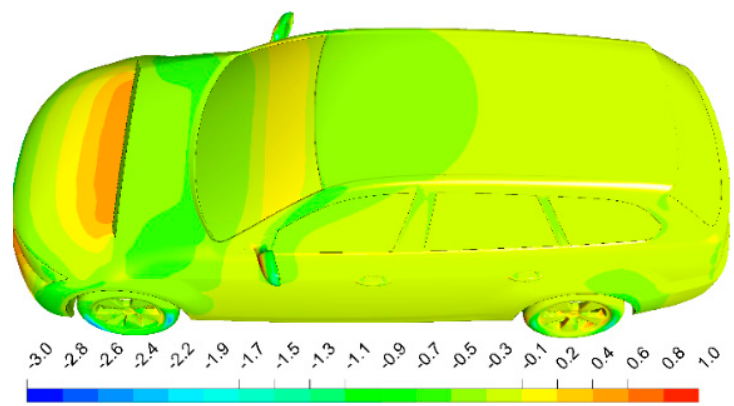

(c)

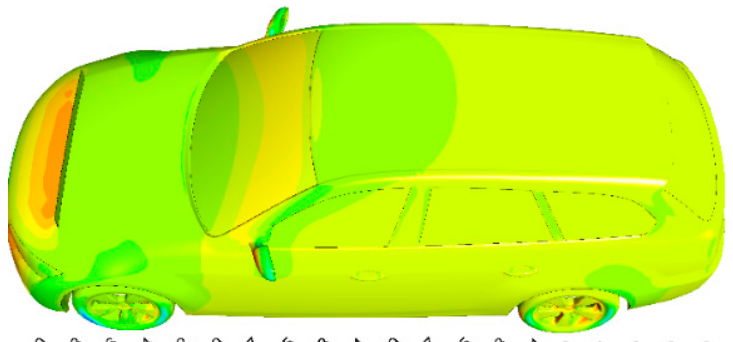

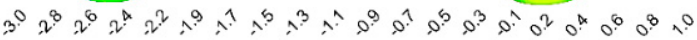

(b)

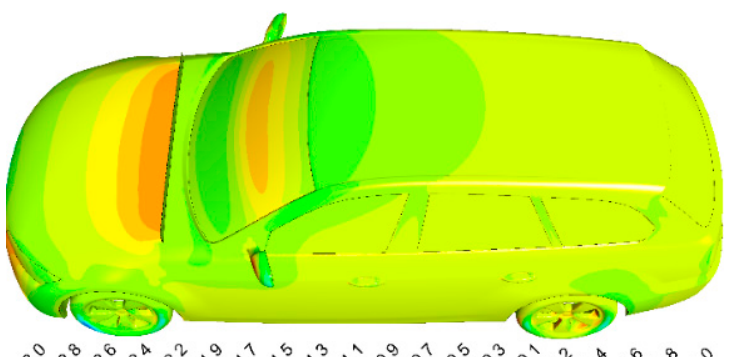

(d)

Figure 11. Pressure coefficient contours on the car body: (a) base case; (b) hood spoiler $0.33 \mathrm{~m}$; (c) hood spoiler $0.66 \mathrm{~m}$; (d) hood spoiler $0.99 \mathrm{~m}$.

Table 3. Aerodynamic coefficients for different locations of the hood spoiler.

\begin{tabular}{ccccc}
\hline \multirow{2}{*}{ Case } & \multirow{2}{*}{$\begin{array}{c}\text { Drag } \\
\text { Coefficient }\end{array}$} & Lift Coefficient & \multicolumn{2}{c}{ Lift Distribution } \\
\cline { 4 - 5 } & & & Front & Rear \\
\hline Base & 0.259 & -0.116 & -0.147 & 0.031 \\
Hood spoiler 0.33 m & 0.304 & -0.156 & -0.083 & -0.072 \\
Hood spoiler 0.66 m & 0.291 & -0.122 & -0.069 & -0.053 \\
Hood spoiler 0.99 m & 0.278 & -0.110 & -0.069 & -0.041 \\
\hline
\end{tabular}

\subsection{Flaps on the Roof in the " $V$ " Pattern}

The first idea of making elements covering the whole roof is to direct the flow from the outer side of the roof towards its centerline. In Figure 12, it can be seen that when the flow streams coming from the two sides of the car meet in the center, pressure on the roof increases (Figure 13). While looking at Figure 13, it can be concluded that the plates that generate the most drag force are located at the front of the roof and on the sides. The selected plates create a set of spoilers inclined at the angle towards the free flow stream, equal to $45^{\circ}$. At the front of the roof, plates create a wedge shape so that the airflow can reach each row of the plates. At the roof's trailing edge, the exact spoiler as in the previous calculations was used. Two cases were studied when the plates were fully ejected and inclined at 45 degrees towards the horizontal plane. Whereas the rear spoiler increased the drag up to 0.402 , the set of plates pushed this value further up to 0.517 (Table 4 ). In both cases, the lift decreases to around -0.32 with a similar lift distribution, with the rear axle gaining more downforce than the front one. 


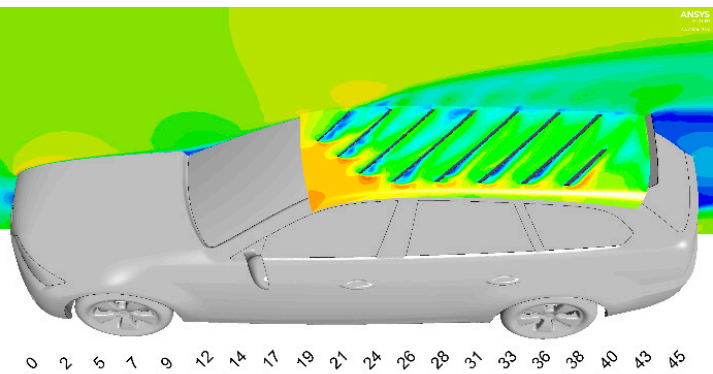

(a)

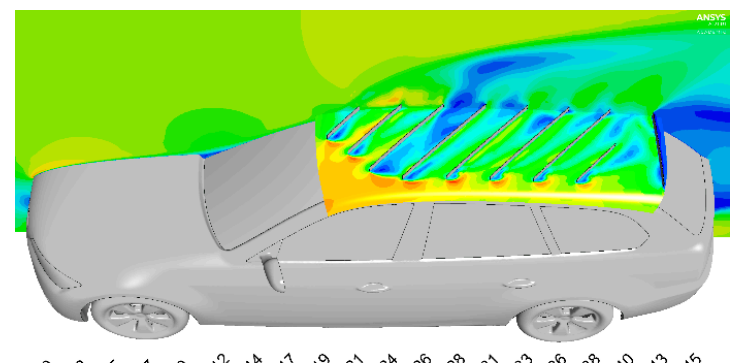

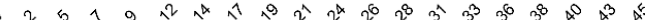

(b)

Figure 12. Velocity contours $[\mathrm{m} / \mathrm{s}$ ] on the symmetry plane and the offset of the roof surface in the middle of the plates, for the plates creating a "V" pattern on the roof, inclined at: (a) $45^{\circ}$ and (b) $90^{\circ}$.

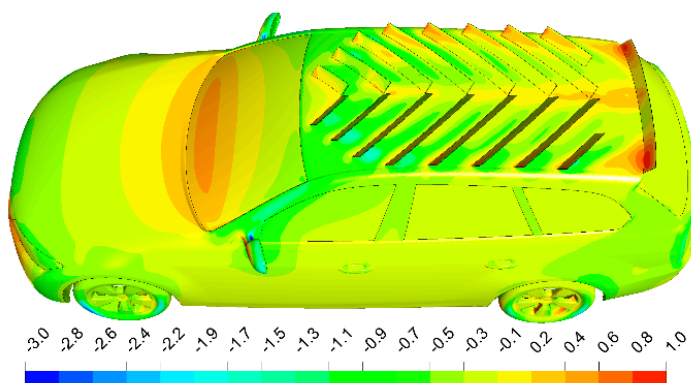

(a)

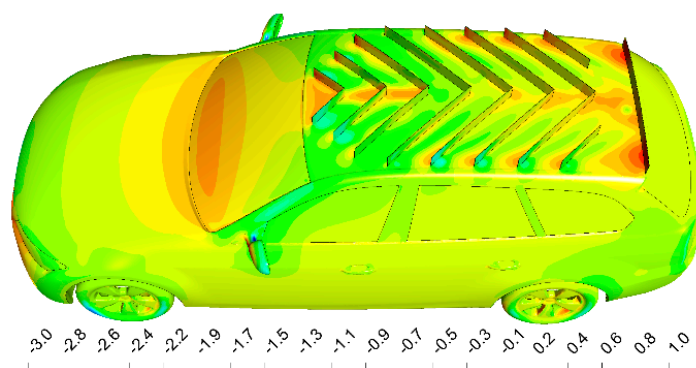

(b)

Figure 13. Pressure coefficient contours on the car body for the plates creating a " $\mathrm{V}$ " pattern on the roof, inclined at (a) $45^{\circ}$ and (b) $90^{\circ}$.

Table 4. Aerodynamic coefficients for flaps creating a " $\mathrm{V}$ " pattern on the roof.

\begin{tabular}{|c|c|c|c|c|}
\hline \multirow{2}{*}{ Case } & \multirow{2}{*}{$\begin{array}{c}\text { Drag } \\
\text { Coefficient }\end{array}$} & \multirow{2}{*}{ Lift Coefficient } & \multicolumn{2}{|c|}{ Lift Distribution } \\
\hline & & & Front & Rear \\
\hline Base & 0.259 & -0.116 & -0.147 & 0.031 \\
\hline Rear spoiler & 0.402 & -0.328 & -0.138 & -0.190 \\
\hline Roof "V" pattern $45^{\circ}$ & 0.433 & -0.241 & -0.106 & -0.135 \\
\hline Roof “V” pattern $90^{\circ}$ & 0.517 & -0.320 & -0.128 & -0.193 \\
\hline
\end{tabular}

The plates are most effective when fully ejected, creating an angle equal to $90^{\circ}$ towards the roof. However, when they are inclined at an angle equal to $45^{\circ}$, their intermediate position still produces more drag than a single spoiler.

\subsection{Flaps on the Roof in the " $A$ " Pattern}

The second approach was to use the flow stream from the centerline of the roof to supply air to each row of the set of plates and direct it sideways. In this case, the flow regime is entirely different from the previous one. The downside of this solution is that the flow stream accelerates at the front edge of the roof (Figure 14), which creates an area of lower pressure (Figure 15), which decreases the downforce on the front axle. On the other hand, the rear spoiler is supplied with more air than before and contributes more to the drag and decrease in lift. As expected, this moves the negative lift distribution towards the car's rear end (Table 5). 


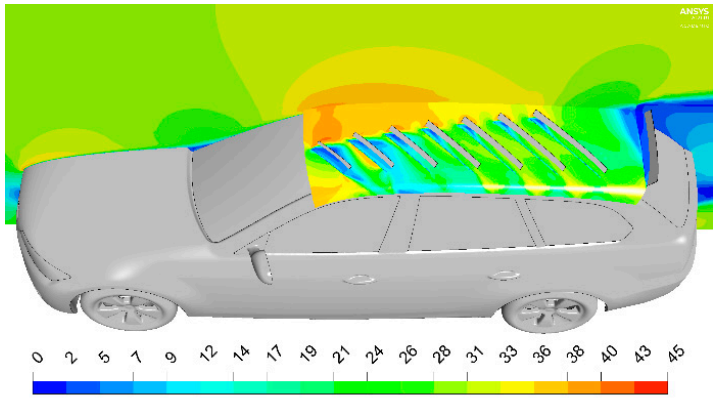

(a)

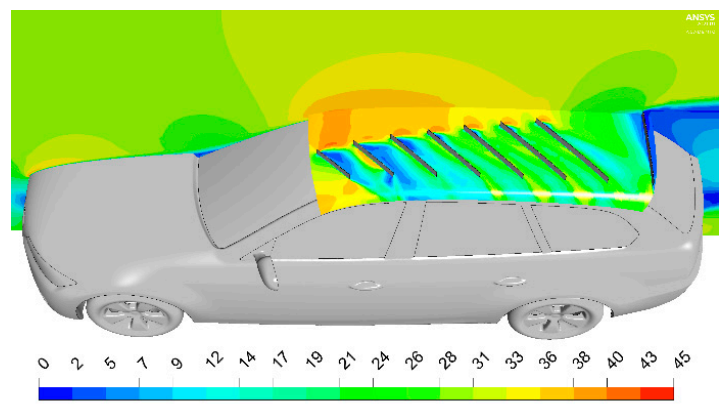

(b)

Figure 14. Velocity contours $[\mathrm{m} / \mathrm{s}]$ on the symmetry plane and the offset of the roof surface in the middle of the plates, for the plates creating an "A" pattern on the roof, inclined at: (a) $45^{\circ}$ and (b) $90^{\circ}$.

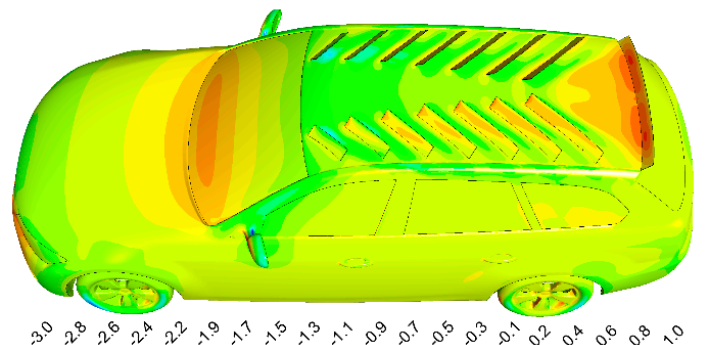

(a)

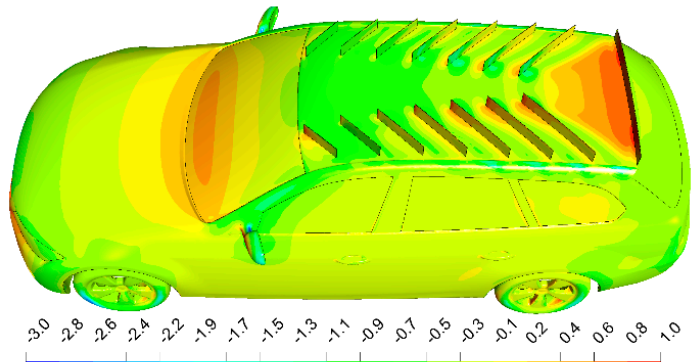

(b)

Figure 15. Pressure coefficient contours on the car body for the plates creating an " $\mathrm{A}$ " pattern on the roof, inclined at (a) $45^{\circ}$ and (b) $90^{\circ}$.

Table 5. Aerodynamic coefficients for flaps creating an " $\mathrm{A}$ " pattern on the roof.

\begin{tabular}{ccccc}
\hline Case & \multirow{2}{*}{$\begin{array}{c}\text { Drag } \\
\text { Coefficient }\end{array}$} & Lift Coefficient & \multicolumn{2}{c}{ Lift Distribution } \\
\cline { 4 - 5 } & 0.259 & -0.116 & Front & Rear \\
\hline Base & 0.402 & -0.328 & -0.147 & 0.031 \\
Rear spoiler & 0.474 & -0.232 & -0.078 & -0.190 \\
Roof "A" pattern $45^{\circ}$ & 0.554 & -0.247 & -0.080 & -0.154 \\
Roof "A" pattern $90^{\circ}$ & & &
\end{tabular}

In this case, the plates inclined at an angle equal to $45^{\circ}$ are more effective, and the gain of rotating them up to $90^{\circ}$ is smaller than before.

\subsection{Flaps on the Hood in the " $V$ " Pattern}

The solutions that were tested on the roof were copied on the hood. Firstly, the "V" pattern results on the hood are presented. In this case, the gain compared to a single spoiler is not as big, but a higher value of drag was still obtained (Table 6). On the other hand, the generated downforce was lower. The drag force that is generated could be higher if not for the fact that when the flow detaches from the hood (Figure 16), the pressure on the center part of the windshield is decreased (Figure 17). A similar phenomenon occurred in the case of a single spoiler. 
Table 6. Aerodynamic coefficients for flaps creating a "V" pattern on the hood.

\begin{tabular}{ccccc}
\hline Case & \multirow{2}{*}{$\begin{array}{c}\text { Drag } \\
\text { Coefficient }\end{array}$} & Lift Coefficient & \multicolumn{2}{c}{ Lift Distribution } \\
\cline { 4 - 5 } & 0.259 & -0.116 & -0.147 & Rear \\
\hline Base & 0.304 & -0.156 & -0.083 & -0.031 \\
Hood spoiler $0.33 \mathrm{~m}$ & 0.293 & -0.122 & -0.070 & -0.052 \\
Hood "V" pattern $45^{\circ}$ & 0.337 & -0.134 & -0.069 & -0.065 \\
\hline Hood "V" pattern $90^{\circ}$ & & &
\end{tabular}

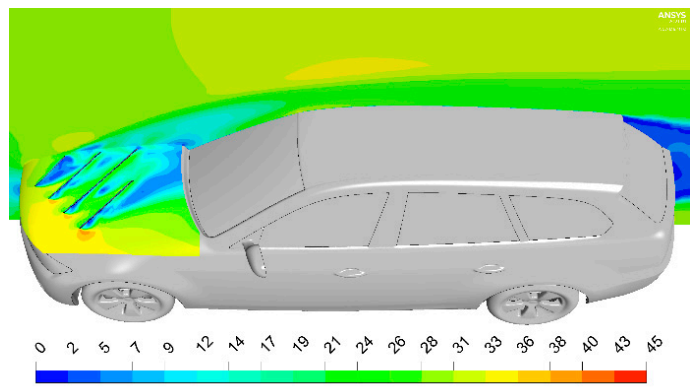

(a)

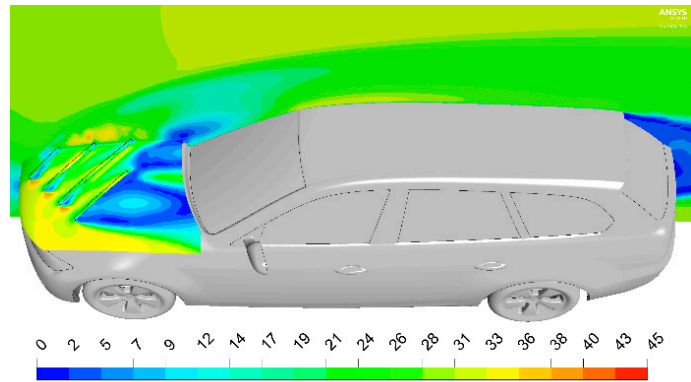

(b)

Figure 16. Velocity contours $[\mathrm{m} / \mathrm{s}]$ on the symmetry plane and the offset of the hood surface in the middle of the plates, for the plates creating a "V" pattern on the hood, inclined at (a) $45^{\circ}$ and (b) $90^{\circ}$.

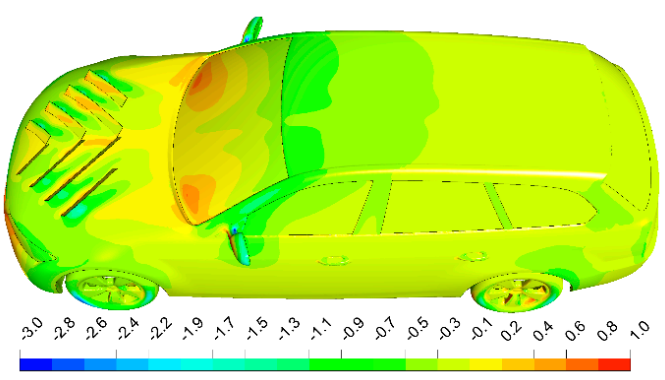

(a)

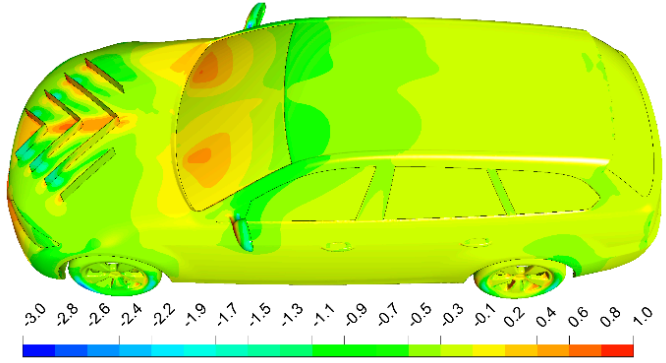

(b)

Figure 17. Pressure coefficient contours on the car body for the plates creating a " $\mathrm{V}$ " pattern on the hood, inclined at (a) $45^{\circ}$ and (b) $90^{\circ}$.

When the plates are inclined at their intermediate inclination angle equal to $45^{\circ}$, values of the generated aerodynamic forces are in between the base case and when they are fully ejected.

\subsection{Flaps on the Hood in the "A" Pattern}

The plates creating an " $\mathrm{A}$ " pattern on the hood were less successful. Whereas the drag was increased to a similar level, the lift was increased, which will deteriorate the car's handling (Table 7). This occurs due to the increase in velocity over the hood (Figure 18), which creates areas of lowered pressure (Figure 19). However, this effect is countered by the increase in pressure around the windshield. Plates inclined at the middle angle produce an increase of the drag and a significantly lower increase in the lift. 
Table 7. Aerodynamic coefficients for flaps creating an " $\mathrm{A}$ " pattern on the hood.

\begin{tabular}{ccccc}
\hline \multirow{2}{*}{ Case } & \multirow{2}{*}{$\begin{array}{c}\text { Drag } \\
\text { Coefficient }\end{array}$} & Lift Coefficient & \multicolumn{2}{c}{ Lift Distribution } \\
\cline { 4 - 5 } & 0.259 & -0.116 & -0.147 & Rear \\
\hline Base & 0.304 & -0.156 & -0.083 & -0.031 \\
Hood spoiler 0.33 m & 0.292 & -0.091 & -0.050 & -0.041 \\
Hood "A" pattern $45^{\circ}$ & 0.323 & 0.018 & 0.027 & -0.009 \\
\hline Hood "A" pattern $90^{\circ}$ & & &
\end{tabular}

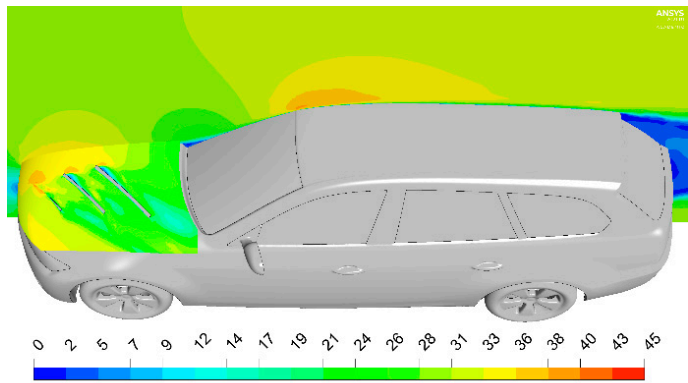

(a)

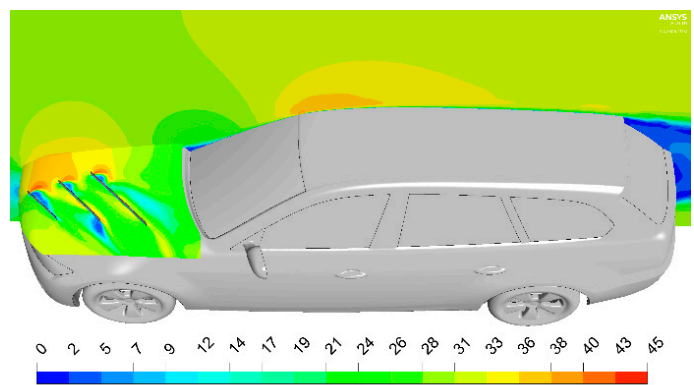

(b)

Figure 18. Velocity contours $[\mathrm{m} / \mathrm{s}]$ on the symmetry plane and the offset of the hood surface in the middle of the plates, for the plates creating an " $\mathrm{A}$ " pattern on the hood, inclined at (a) $45^{\circ}$ and (b) $90^{\circ}$.

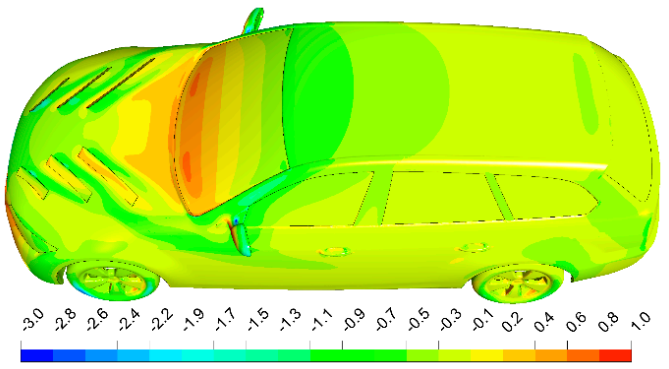

(a)

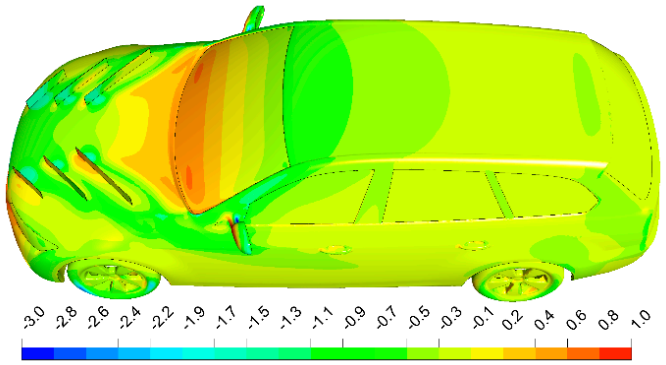

(b)

Figure 19. Pressure coefficient contours on the car body for the plates creating an " $A$ " pattern on the hood, inclined at (a) $45^{\circ}$ and (b) $90^{\circ}$.

\subsection{Flaps on the Hood and the Roof in the "V" Pattern}

The final step was to investigate whether the performance of the plates mounted on the roof would be significantly influenced by the elements on the hood and decrease their effectiveness. As it can be seen in Table 8, combining both of these cases increases the drag as well as the downforce. The detachment zone created on the centerline of the car that starts on the hood (Figure 20) does not degrade the performance of the plates on the roof. What is more, the increase in pressure on the centerline of the roof (Figure 21) is even more significant than before, as it can be compared with Figure 13.

Table 8. Aerodynamic coefficients for flaps creating a " $\mathrm{V}$ " pattern on the roof and the hood.

\begin{tabular}{ccccc}
\hline Case & \multirow{2}{*}{$\begin{array}{c}\text { Drag } \\
\text { Coefficient }\end{array}$} & Lift Coefficient & \multicolumn{2}{c}{ Lift Distribution } \\
\cline { 4 - 5 } & 0.259 & -0.116 & Front & Rear \\
\hline Base & 0.517 & -0.320 & -0.147 & 0.031 \\
Roof "V" pattern 90 & 0.337 & -0.134 & -0.069 & -0.193 \\
Hood "V" pattern 90 & 0.453 & -0.216 & -0.093 & -0.123 \\
Hood + Roof "V" pattern 45 & 0.609 & -0.377 & -0.126 & -0.251 \\
Hood + Roof "V" pattern 90 $90^{\circ}$ & &
\end{tabular}




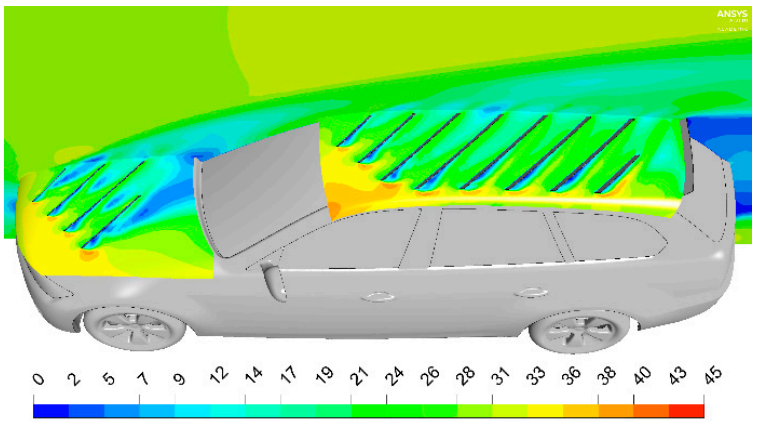

(a)

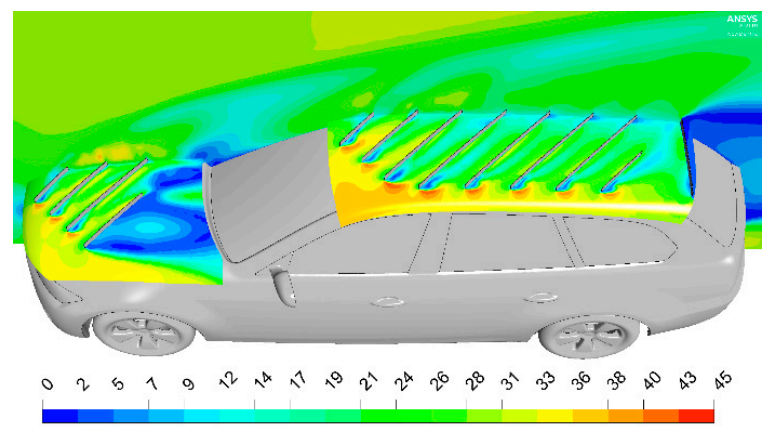

(b)

Figure 20. Velocity contours $[\mathrm{m} / \mathrm{s}$ ] on the symmetry plane and the offsets of the hood and the roof surfaces in the middle of the plates, for the plates creating a " $\mathrm{V}$ " pattern on the hood and the roof, inclined at (a) $45^{\circ}$ and (b) $90^{\circ}$.

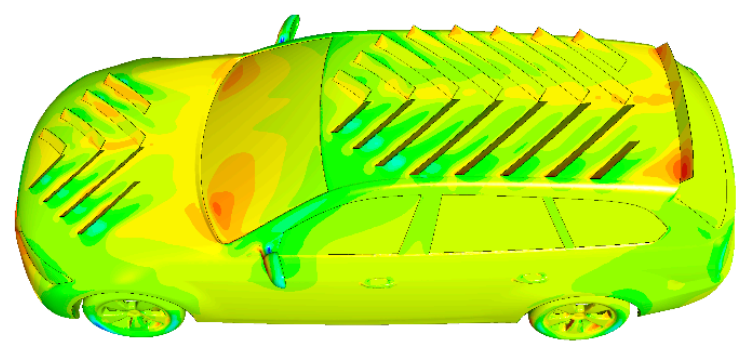

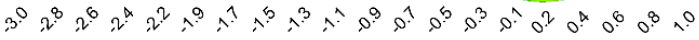

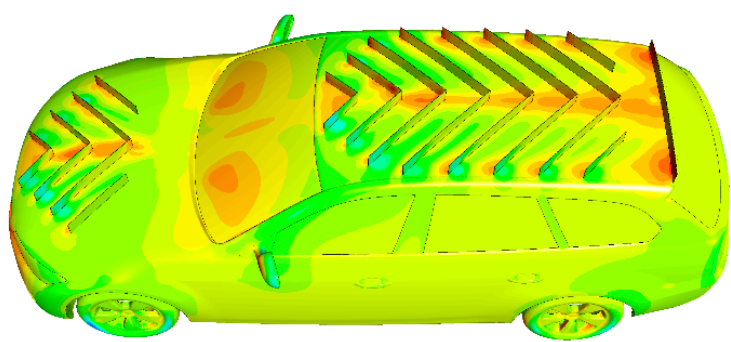

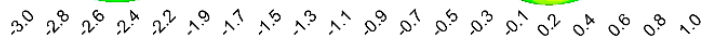

(b)

(a)

Figure 21. Pressure coefficient contours on the car body for the plates creating a " $\mathrm{V}$ " pattern on the hood and the roof, inclined at (a) $45^{\circ}$ and (b) $90^{\circ}$.

\subsection{Flaps on the Hood in the " $A$ " Pattern}

As well as in the previous case, combining the configurations with plates on the hood and the roof improved the aerodynamic properties of the car (Table 9). As mentioned before, the downside of this configuration is that the velocity is increased in the front of the hood and the front of the roof (Figure 22). This contributes to an increase in lift. On the other hand, the pressure increase around the windshield and the rear spoiler (Figure 23) is more significant than in any other case.

Table 9. Aerodynamic coefficients for flaps creating an "A" pattern on the roof and the hood.

\begin{tabular}{ccccc}
\hline Case & \multirow{2}{*}{$\begin{array}{c}\text { Drag } \\
\text { Coefficient }\end{array}$} & Lift Coefficient & \multicolumn{2}{c}{ Lift Distribution } \\
\cline { 4 - 5 } & 0.259 & -0.116 & Front & Rear \\
\hline Base & 0.554 & -0.247 & -0.080 & -0.031 \\
Roof "A" pattern 90 & 0.323 & 0.018 & 0.027 & -0.009 \\
Hood "A" pattern 90 & 0.506 & -0.190 & -0.042 & -0.148 \\
Hood + Roof "A" pattern 45 & 0.604 & -0.084 & 0.035 & -0.119 \\
Hood + Roof "A" pattern 90 & & &
\end{tabular}




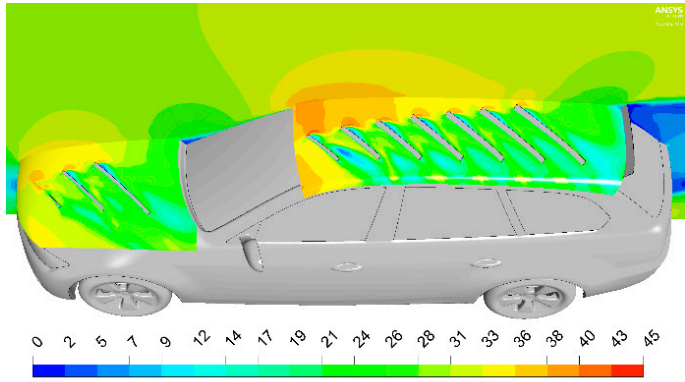

(a)

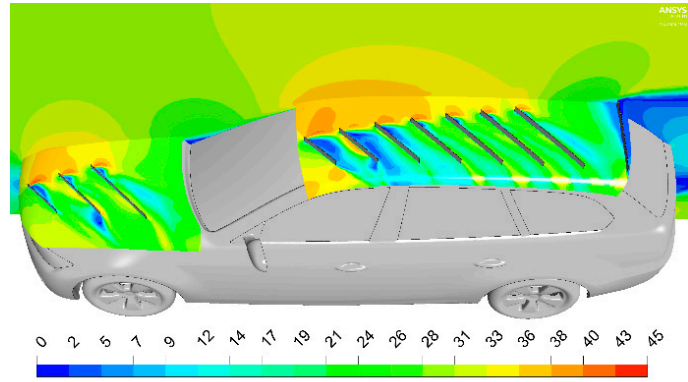

(b)

Figure 22. Velocity contours $[\mathrm{m} / \mathrm{s}$ ] on the symmetry plane and the offsets of the hood and the roof surfaces in the middle of the plates, for the plates creating an " $\mathrm{A}$ " pattern on the hood and the roof, inclined at (a) $45^{\circ}$ and (b) $90^{\circ}$.

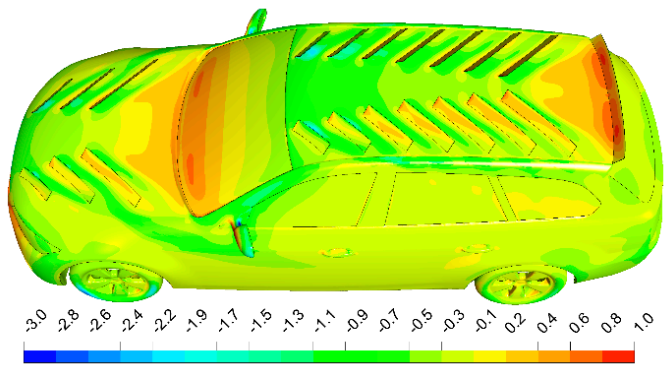

(a)

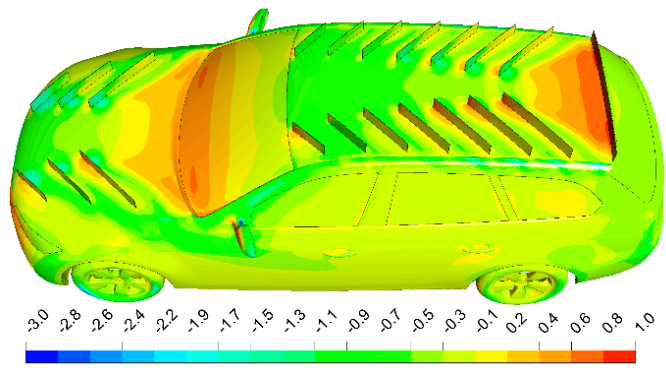

(b)

Figure 23. Pressure coefficient contours on the car body for the plates creating an " $A$ " pattern on the hood and the roof, inclined at (a) $45^{\circ}$ and (b) $90^{\circ}$.

\section{Discussion}

The patterns of plates presented in this paper proved that this kind of active aerodynamic system could be beneficial. The focus of this work was put on a configuration that could work as an airbrake. To put the findings of this article in a broader context, the maximum drag increase that was achieved was equal to 0.35 and is compared in Table 10 with values of drag increase for some of the cars equipped with airbrakes. The cars brought up in Table 10 were either prototypes, sports cars, or super/hyper-cars. In most cases, the airbrake utilized had a form of a spoiler or a rear wing of significant size, so these were devices that needed a robust control system. The airbrake mechanism presented in this article works entirely differently and gives good results and other functionalities such as a much quicker activation time, so it seems worthy of further investigation.

Table 10. Examples of drag coefficient values increase for cars equipped with airbrakes.

\begin{tabular}{cc}
\hline Case & $\begin{array}{c}\text { Drag Coefficient Increase after the } \\
\text { Airbrake Is Activated }\end{array}$ \\
\hline DrivAer model with moving plates in this study & 0.35 \\
Mercedes-Benz 300 SLR (1950's) & $0.406[18]$ \\
Mitsubishi HSR II (1989) & $0.210[19]$ \\
Bugatti Veyron 16.4 Super Sport (2011) & $0.347[20]$ \\
Bugatti Chiron Sport (2018) & $0.240[21]$ \\
Honda CR-X del Sol with a prototype airbrake (2019) & $0.580[22]$ \\
\hline
\end{tabular}

The estate type DrivAer baseline aerodynamic load distribution of the front and rear wheels is unfavorable. Specific plate configurations can significantly increase the rear wheels' aerodynamic downforce, temporarily improving the vehicle's handling during cornering. 
The future work leaves plenty of room for optimization techniques to find the most effective patterns of plates on the car body and the size and shape of plates. Another direction that could be taken in future work is to find plate patterns that would improve the car's handling during a gust of wind or cornering by generating the side forces that would negate the disadvantageous effects in such conditions. There is also a need to perform calculations in an unsteady state to see what happens when the plates eject.

\section{Conclusions}

The results presented in this paper prove that small aerodynamic elements covering the whole car body can be utilized to generate substantial aerodynamic loads. Furthermore, while they increase the complexity of the car design, they can provide additional benefits compared to the use of typical aerodynamic devices such as spoilers or wings. Their main benefit is that they can be adjusted much faster than one big element, and they can also be incorporated more easily into the car design, which is not possible where a big standalone device such as a rear wing is concerned.

Author Contributions: Conceptualization, K.K. (Krzysztof Kurec), K.K. (Konrad Kamieniecki) and J.P.; methodology, K.K. (Krzysztof Kurec), K.K. (Konrad Kamieniecki) and J.P.; software, K.K. (Krzysztof Kurec), K.K. (Konrad Kamieniecki); validation, K.K. (Krzysztof Kurec); formal analysis, K.K. (Krzysztof Kurec), K.K. (Konrad Kamieniecki) and J.P.; investigation, K.K. (Krzysztof Kurec), K.K. (Konrad Kamieniecki) and J.P.; resources, K.K. (Krzysztof Kurec), K.K. (Konrad Kamieniecki) and J.P.; data curation, K.K. (Krzysztof Kurec), K.K. (Konrad Kamieniecki); writing—original draft preparation, K.K. (Krzysztof Kurec); writing-review and editing, K.K. (Konrad Kamieniecki) and J.P.; visualization, K.K. (Krzysztof Kurec); supervision, J.P. All authors have read and agreed to the published version of the manuscript.

Funding: This research received no external funding.

Data Availability Statement: Data supporting reported results is contained within the article.

Conflicts of Interest: The authors declare no conflict of interest.

\section{References}

1. Ahmad, E.; Iqbal, J.; Arshad Khan, M.; Liang, W.; Youn, I. Predictive Control Using Active Aerodynamic Surfaces to Improve Ride Quality of a Vehicle. Electronics 2020, 9, 1463. [CrossRef]

2. Chen, Z; $\mathrm{Wu}, \mathrm{Y}$;; Li, F. Integrated Control of Differential Braking and Active Aerodynamic Control for Improving High Speed Stability of Vehicles. Int. J. Automot. Technol. 2020, 21, 61-70. [CrossRef]

3. De Carvalho Pinheiro, H.; Russo, F.; Sisca, L.; Messana, A.; De Cupis, D.; Ferraris, A.; Airale, A.G.; Carello, M. Advanced vehicle dynamics through active aerodynamics and active body control. In Proceedings of the Proceedings of the ASME Design Engineering Technical Conference; American Society of Mechanical Engineers (ASME): Virtual, Online, 17-19 August 2020; Volume 4.

4. Piechna, J. A Review of Active Aerodynamic Systems for Road Vehicles. Energies 2021, 14, 7887. [CrossRef]

5. Szudarek, M.; Piechna, J. CFD Analysis of the Influence of the Front Wing Setup on a Time Attack Sports Car's Aerodynamics. Energies 2021, 14, 7907. [CrossRef]

6. Katz, J. Aerodynamics in motorsports. Proc. Inst. Mech. Eng. Part P J. Sport. Eng. Technol. 2021, 235, 324-338. [CrossRef]

7. Kurec, K.; Piechna, J. Influence of side spoilers on the aerodynamic properties of a sports car. Energies 2019, 12, 4697. [CrossRef]

8. Anne Forschner Instagram Account. Available online: https://www.instagram.com/anne_forschner/ (accessed on 7 December 2021).

9. Mercedes-Benz VISION AVTR. Available online: https://www.mercedes-benz.com/en/vehicles/passenger-cars/mercedesbenz-concept-cars/vision-avtr/ (accessed on 7 December 2021).

10. Riccio, A.; Sellitto, A.; Ameduri, S.; Concilio, A.; Arena, M. Shape memory alloys (SMA) for automotive applications and challenges. In Shape Memory Alloy Engineering; Elsevier: Amsterdam, The Netherlands, 2021; pp. 785-808.

11. Sellitto, A.; Riccio, A. Overview and Future Advanced Engineering Applications for Morphing Surfaces by Shape Memory Alloy Materials. Materials 2019, 12, 708. [CrossRef]

12. Cozmei, M.; Hasseler, T.; Kinyon, E.; Wallace, R.; Deleo, A.A.; Salviato, M. Aerogami: Composite origami structures as active aerodynamic Ccontrol. Compos. Part B Eng. 2020, 184, 107719. [CrossRef]

13. Heft, A.I.; Indinger, T.; Adams, N.A. Introduction of a New Realistic Generic Car Model for Aerodynamic Investigations. In SAE Technical Paper. Available online: https:/ / doi.org/10.4271/2012-01-0168 (accessed on 7 December 2021). 
14. Dang, A. Mercedes Vision AVTR—Sketches. Available online: https://alexdang.artstation.com/projects/GXwmoW (accessed on 7 December 2021).

15. Ashton, N.; West, A.; Lardeau, S.; Revell, A. Assessment of RANS and DES methods for realistic automotive models. Comput. Fluids 2016, 128, 1-15. [CrossRef]

16. Avadiar, T.; Thompson, M.C.; Sheridan, J.; Burton, D. Characterisation of the wake of the DrivAer estate vehicle. J. Wind Eng. Ind. Aerodyn. 2018, 177, 242-259. [CrossRef]

17. Varney, M.; Passmore, M.; Wittmeier, F.; Kuthada, T. Experimental Data for the Validation of Numerical Methods: DrivAer Model. Fluids 2020, 5, 236. [CrossRef]

18. Falkovén, A.; Nordin, J.; Rama, K.; Rask, A.; Sjöstrand, P.; Stadler, M. CFD-analysis of the aerodynamic properties of a MercedesBenz 300SLR. Bachelor's Thesis, Chalmers University of Technology, Gothenburg, Sweden, 2015.

19. Kataoka, T.; China, H.; Nakagawa, K.; Yanagimoto, K.; Yoshida, M. Numerical Simulation of Road Vehicle Aerodynamics and Effect of Aerodynamic Devices. SAE Trans. 1991, 100, 722-734.

20. Bugatii Veyron 16.4 Super Sport-Technical Specifications. Available online: https://assets.bugatti.com/fileadmin/media/ Media/Veyron/Super_Sport/Technical_Specifications_Bugatti_Veyron_16.4_Super_Sport.pdf (accessed on 7 December 2021).

21. Bugatti Chiron Sport-Technical Specifications. Available online: https://newsroom.bugatti/models/specifications/chironsport/180724_technical_specifications_bugatti_chiron_sport.pdf (accessed on 24 March 2019).

22. Kurec, K.; Remer, M.; Piechna, J. The influence of different aerodynamic setups on enhancing a sports car's braking. Int. J. Mech. Sci. 2019, 164, 105140. [CrossRef] 